\title{
University Library Services in Sri Lanka: a Historical Perspective
}

\author{
Sumana Jayasuriya* \\ BA (Hons), PG Dip in LIS (Sri Lanka), MLS (Phillippines), Hon Fellow SLLA
}

\begin{abstract}
Development of libraries is closely linked to and depends on the development of its parent organization, the university. The expansion of university education and the establishment of universities to cater to the needs of those seeking higher education had a tremendous impact on the development and services provided by the libraries. The expansion of libraries under different time periods, Collection development, Staff structure \& staff training, Library governance, and Automation of library operations since the inception of the University of Ceylon in 1942 are discussed.
\end{abstract}

Key words: University libraries; Sri Lanka. Libraries; Library services, Library governance

\section{Pre-University era}

Sri Lanka records a rich intellectual and literary tradition built around Mahavihara, Abhayagiriya and Jethavana vihara, the seats of Buddhist learning during the Anuradhapura period from $250 \mathrm{BC}$ to $1017 \mathrm{AD}$. Feature of the Buddhist temples was their libraries of books on oriental studies and Buddhism which attracted many scholars from Asian countries; India, Burma, and China. However, Buddhism along with the educational activities suffered a setback with the foreign domination from the beginning of the $16^{\text {th }}$ century. The real set back became evident with Ceylon becoming a colony of the British in 1815 and indigenous education associated with Buddhist temples lost the patronage of the British rulers.

\section{*Librarian, University of Colombo \\ E-mail: sumanaj@lib.cmb.ac.lk}


After the coastal areas of the country came under the Western powers, education fell into the hands of Christian missionaries and only four percent of the population could reach higher education as the medium of instruction was English. The demand for institutions of higher learning had existed in some of the British colonies from the last quarter of the $19^{\text {th }}$ century and the pressure gained momentum at the turn of the century. De Silva (unpublished) point out that change to develop higher education in the country came with the recommendations made by the Colebrooke Commissioners who submitted their report in 1832. Initial step was the establishment of the

Colombo Academy in 1835, followed by the establishment of Colombo Medical College in 1870 and the Law College in 1874. The proposal for the establishment of a University of Ceylon was first proposed publicly in the early years of the last century, when a number of public-spirited citizens led by Sir Ponnambalam Arunachalam formed the Ceylon University Association, but until 1911 no active steps were taken by the Government.

The outbreak of the World war postponed the establishment of the university college but in January 1921, the University College was officially opened in "Regina Walawwa" (now College House) at Colombo admitting 166 students. The University College was not an autonomous college organized like a university but established as part of the University of London's overseas academic network, and remained as the only university level institution up to 1942. Science section of the Technical College became the nucleus of the Dept. of Science of the Ceylon University College. The University College was regarded as a half-way house to a national university. 


\section{Establishment of University of Ceylon:}

The initial step to establish an autonomous university came with the Buchanan-Riddell commission report published in January 1929 which is considered as one of the most important state papers in the history of higher education in Sri Lanka. It not only outlined the steps necessary to establish a unitary and residential university at a site near Kandy but also prepared a draft constitution for such a university which greatly influenced the 1942 constitution of the University of Ceylon.

By this time a well developed primary and secondary education system was in place, and professional and technical education at a post-secondary level had been established earlier. These institutions were all state controlled and financed. Therefore, post-secondary education and university education was very much the apex of a solid pyramid.

University of Ceylon was established in 1942, incorporating the Ceylon Medical College, and the Ceylon University College and remained as the only institution of University rank until 1958. The university was to be located at Peradeniya, as a residential university, and several buildings complexes were needed before the university could be shifted to new premises. The move to Peradeniya was done in several stages. By 1952 faculties of Arts, Oriental Studies Agriculture, Veterinary sciences and Laws were moved to Peradeniya. Later faculty of Science and Engineering was shifted but Medical faculty remained in Colombo due to the need for hospital facilities.

\section{Development of university libraries:}

Development of a library is closely associated with the development of the parent organization of which it forms a part. The importance of a university 
library is shown in the report of the University Grants Committee of Great Britain, 1921 (cited in Goonethileke, 1975):

"The character and efficiency of a university may be gauged by the treatment of its central organ, the Library. An adequate Library is not only the basis of all teaching and study; it is the essential condition of research without which additions cannot be made to the sum of human knowledge."

The changes taking place at various stages in the evolution of the present university system had a huge impact on the development of libraries. Four distinct periods of development could be identified in the development of libraries: i. University College 1921-1942; ii. University of Ceylon 1942 -1958; iii. Four autonomous universities 1959 - 1972 \& a single university with campuses 1972 -1978; iv. autonomous universities with a centralized administrative body (UGC) 1978 to the present.

\section{University College 1921-1942:}

The University College library was established in one of the rooms of 'College House' with a donation approximately 2,500 books by Sir Ponnambalam Arunachalam in memory of his son A. Padmanabha in 1921. The Library was given an annual grant of Rs. 750 to acquire materials. In 1923, the Library was shifted to 'Villa Venezia' a more spacious location in the vicinity. Mr. R. S. Enright was first university librarian appointed in 1925 and served the university until his demise in November 1952. He emphasized the need to have proper classification system and recommended the use Dewey Decimal Classification (DDC) in 1929. DDC has taken root in most of the university and other libraries in Sri Lanka which proves that Mr. Enright had a correct vision. In 1952 the last year of his service the collection had 80,000 items, and the allocation had increased from Rs. 750 to Rs. 150,000 per annum. Former 
librarian of Peradeniya University Mr. Senadeera describes him thus: "Mr. Enright also had a lofty concept of duty which helped him maintain a high level of library service". At the formative years, the university of Ceylon library was fortunate in having a committed, dedicated librarian who had a vision of providing a high quality service to the community.

\section{University of Ceylon 1942 -1958:}

According to Jennings there was an acute shortage of materials in the library and the vote for library books was increased to Rs. 125,000 when the University of Ceylon was established. After 21 years of University College the library had only 30,000 volumes but within seven years it was doubled and the library was acquiring materials at the rate of 10,000 volumes per year. The plans were that library building could accommodate 500,000 volumes. According to Jennings opportunities for research was limited because of the small collections, and "it was possible to undertake the sort of research which is often known as 'interpretation', the re-assembly of known material in such a way as to lead to new conclusions, but even this may require a large library."(2005, p.104)

Jennings also talks of "our cultural heritage" and he felt that this knowledge should be made available to undergraduates and graduates. He strived to get the Archives allocated to Peradeniya and had space reserved for it, however his idea was not favoured by the then Government, for reasons which Jennings believe is superfluous. If he was able to get a decision is his favour the history of the Peradeniya library would have taken a different turn.

Jennings further states: "There is no library worth mentioning in Ceylon: and the only library which is likely to be worth mentioning in the next twenty years (at least) is the University Library in Peradeniya. Our Ceylon collection is by no 
means perfect, for we really began in 1942, but it is improving. Besides, we have the background material which no other library possesses. This material is essential for an adequate use of the Archives, and if the Archives are located in Colombo it will be necessary for scholars to "commute" between Colombo and Peradeniya." (2005, p.188)

According to the University of Ceylon Calendar 1954/1955, the University library contained approximately 94,000 volumes, which included several donations. In addition to the collection, books relating to various subjects in the Science, Engineering, and Medical faculties were housed in their respective departments. There was a separate branch library for books on Education and Mathematics which was retained in Colombo.

The Main library was divided into three sections: Reference Library and reading rooms, Lending library, and the Law library. The Reference library was open from 8.00 a.m. to 7.00 p.m. on week days and 8.00 a.m. to 12.30 p.m. on Saturdays. Reference books were also issued for overnight reference. The periodical collections were bound and made available for reference.

The graduates and graduates of other universities were allowed reference facilities after paying an annual registration fee of Rs. 10 . Rules and regulations with regard to borrowing facilities, fines for overdue books, behavior inside the library was in place at this time.

\section{Period from 1958 to 1972:}

There was an unprecedented expansion of universities without proper evaluation during this period. The introduction of the Free Education bill in 1944 which changed the medium of instruction in schools to Sinhala and Tamil had a tremendous impact on the education of the population. With the change 
of the new government in 1956, the university was being pressed with regard to two issues; an increase in the intake of students - especially in the arts and social sciences - and a change in the medium of instruction from English to Sinhala and Tamil. As a quick solution to these problems, universities were established by upgrading institutes of higher learning already existed and all these institutes had substantive collections which formed the nucleus of its library collections.

- University of Kelaniya in 1959 by upgrading the Vidyalankara Pirivena established in 1875 at Peliyagoda,

- Vidyodaya university in 1959 by upgrading the Vidyodaya Pirivena established in 1873 at Maligakanda,

- University of Colombo in 1967 by granting autonomous status to University of Ceylon which up to now functioned as University of Ceylon at two sites: Peradeniya and Colombo,

- University of Moratuwa in 1972 by upgrading the Ceylon College of Technology at Katubedde

- University of Jaffna (1974)

The Vidyalankara and Vidyodaya Pirivena's were two seats of highest Buddhist learning which preserved the local literary traditions. Both these institutions had very rich and rare collections on Buddhism, Buddhist studies, Pali, Sanskrit, history and oriental studies. At the beginning the Vidyalankara and Vidyodaya universities admitted only male students.

At the beginning, the library of the Vidyalankara pirivena was housed in a small building which was known as the 'Poya ge' at the Pirivena premises, and there 
were 15,000 books, and manuscripts in the collection. Later, 4,000 materials were added (University of Kelaniya, news letter).

The main focus of libraries was to develop undergraduate collections and to provide reference \& lending services. Harold V. Bonny, UNESCO Adviser who submitted a report on "Library Services for Ceylon" (1959) referring to Library of the Ceylon University, Peradeniya says that the library had a book stock of 135,121 , and 35,041 book transactions took place that year. The expenditure on books and periodicals was Rs. 247,976 . The library had four qualified staff and considerable technical work was in progress.

Bonny further states that the book stock of both Vidyodaya and Vidyalankara universities were 13,000 each but the annual allocation was Rs. 75,000 and Rs. 50,000 respectively. Both libraries had acute accommodation problems, and the Vidayalankara university library access was given only to the final year students. However, he mentions that Vidyalankara library had a well catalogued (dictionary) and classified library. They also used Browne system for circulation.

To cope up with the growing demand for university education The Universities Act No. 1 of 1972 brought the four existing universities, and newly established Jaffna campus under one single "University of Ceylon", and the universities became campuses functioning under one single university. The College of Technology library and Jaffna College library collections made the nucleus of libraries for the newly founded campuses at Katubedde and Jaffna.

\section{Period after 1978:}

With the enactment of Universities Act No. 16 of 1978, the campuses were given autonomous status. Six new universities were established under the 
new Act: University of Ruhuna (1978 as a campus and 1984 as a university), Dumbara campus of the University of Peradeniya in 1979, Open University of Sri Lanka incorporating the External Services Agency and the Sri Lanka Institute of Distance Education in 1980, and the Batticaloa University College in 1981.

The new universities especially the regional universities faced many challenges. The challenges which inhibited the development of libraries were the failure to attract trained staff, lack of finances, development of collection, and buildings.

Address by Dr. Stanley Kalpage, Secretary to the Ministry of Higher Education and the Chairman, UGC at the inaugural seminar on 'Library Management' held on $02^{\text {nd }}$ May 1987, at the Sri Lanka Foundation Institute reveal the status of university libraries at the time. In his address he states that he was directed by His Excellency the President of Sri Lanka, who was also the Minister of Higher Education to provide him with full information on the different university libraries and to suggest ways and means of raising their standards. All Vicechancellors and Librarians participated at this meeting to discuss the state of university libraries.

At the time, disbursement of funds of the government grant was done on the basis of the preceding year's grant adjusted upwards for some inflation, salary increments and new posts approved. There were no approved formulae for allocating funds to the different faculties and the library. The library allocation which forms a part of the capital allocation was not diverted in a fair manner. In some years the librarians have complained of a scarcity of funds for books and periodicals while the funds received from the Treasury has been accumulated unspent. He questions as why such large amounts of money were 
left to be accumulated rather than spending them on acquisition of materials for the library. (Kalpage, 1988)

The problems recognized by librarians inhibiting the development of university libraries were identified as lack of adequate space, shortage of trained staff, the absence of modern technology and inadequate funds. Some important decisions were taken at the meeting. These were to re-activate Library Committees, introduce computerized systems, to set up a post-graduate institute of Library and Information Science for training of staff. At this meeting where Professor Paul Wasserman of USA and Professor Frank N. Hogge, UK two academic librarians of repute were present, it was accepted that the universities had problems regarding space, staff, technology and funds which inhibited the development. However, at the time there were several library buildings in progress, but according to Kalpage "the most of the planning is on conventional lines on the assumption that a library is a mere depository for books and periodicals."

He further mentions the fact that the universities are handicapped by the paucity of trained library professionals and the libraries had not received priority for training of staff. Awards for foreign training have been limited, and the facilities available locally needed improvement.

He concludes by saying that there is a need for a "master plan for the development of university libraries with specific targets for achievement in the short and medium terms. An overall strategy for the attainment of these targets in the system as a whole and in the individual institutions should take into account presently available resources and suggestions for harnessing additional resources. When all this has been done, the management of our libraries and training of library personnel." 
Dr. Kalpage was a man of great vision who supported the development of libraries. He as the Secretary of the Ministry of Higher Education and the Chairman of the UGC allocated two commonwealth scholarships annually for the training of library professionals. However, only two assistant librarians were able to make use of this opportunity as the offer was not extended after his term of office as the Chairman of the UGC.

\section{Collection development:}

During its formative years, the university of Ceylon library paid considerable attention to develop the undergraduate collections, periodical collections, acquisition of research materials, Ceylon collections, staff training and space and equipment, and stream lined the services to its readers. The libraries were organized using the functional divisions such as Reader Services, Technical services, Acquisitions, Periodicals.

Library materials were acquired through purchases, exchange agreements for university publications (University of Ceylon Review and The Ceylon Journal of Science) and donations. Number of journal title subscribed increased from 1100 in 1952 to 1400 in 1957 . Cordial relationship was maintained with the faculties and recommendations were obtained from the academics before placing orders for books and periodicals. University of Peradeniya had a distinct advantage of becoming a legal depository library in 1952, the privilege which they enjoy up to now. With the absence of a National library in the country this library served as a national library, and started to fulfill some of the functions of the National library. Provision of bibliographical services to South-Asia Science Co-operation Office at New Delhi and the International Committee on Documentation of Social Sciences at Paris commenced during this period. 
Entire collections were organized using DDC and the Anglo-American Cataloguing Rules (AACR). Classified card catalogues were maintained for the collections. Brown system was used for circulation of library materials. The general collection was divided as Reference and Lending collections, and the undergraduates were allowed to borrow them for different periods of time. In addition, there were special collections such as Ceylon collection, Permanent Reference, Manuscript collections, bound periodicals reserved only for reference inside the library.

Goonetilleke (1975) talking of the attitudes of the librarians, opines that "In a period of rapid and dynamic change in all fields of higher education, the place and function of the library have yet to be considered dispassionately by university librarians, who seem content to tackle the day to day problems of routine administration as they arise, without lifting their gaze to wider and more purposeful horizons." (P. 130)

He further states that the gradual decline of the library in performing it services is seen by "the severely constricted perspective of the library as a mere provider of books and periodicals (and text books in multiple copies at that nowadays) needs to be drastically widened to enable it to project a more positive and dynamic image of itself to the undergraduate in particular. The conventionally comfortable and lethargic view of providing the basic minimum of service and letting the readers sink or swim, ignore and neglects the social revolution which has been taking place in universities over the last twenty years." (p.132)

Whenever changes occurred in the curriculum, it affected the collections of libraries. In 1952 when the decision was taken to transfer the university to the new site at Peradeniya the main collections were shifted except medical and 
science collections. Same was true when the Law faculty was shifted from Peradeniya to Colombo. In 1974 when the Faculties of Education of three universities merged, the collections of Education books at Peradeniya, Vidyodaya and Vidyalankara libraries were transferred to University of Colombo. This created several problems of ownership marking, disorganization of card catalogues, shelf lists and shelving.

\section{Library Governance:}

According to the University Ordinance No. 20 of 1942 the Librarian is one of the three principal full-time officers of the University, along with the Vicechancellor and the Registrar. He has occupied the same important position in the subsequent Acts, including the Universities Act, No. 16 of 1978 which is in force at present. According to the 1942 Ordinance, "the Librarian shall be responsible for the administration and care of the University Library or Libraries". His salary has been equated to a professor but under this Ordinance the Library staff has been categorized under the non-academic staff.

The duties of the Assistant Librarian are also outlined in the Ordinance, 'the duty of an Assistant Librarian shall be to assist the Librarian in the performance of his duties under Statute XIV, and the distribution of work shall be arranged by the Librarian in consultation with the Vice-chancellor. During the absence of the Librarian for any cause, an Assistant Librarian may be appointed by the Vice-Chancellor to exercise any of the function of the Librarian without extra remuneration.'

The Higher Education Act No. 20 of 1966 proposed a Library Committee of the Senate which has been included in the subsequent Acts. For the first time the Librarians are categorized under the term "Teacher", thus granting academic 
status to senior Library staff. In Part XI: Appointment to the staff of a University. 64 (8) of the Act: "Professor shall be deemed to include a Librarian and 'Teacher' shall be deemed to include an Assistant Librarian."

The University of Ceylon Act No. 1 of 1972, which created one university with several campuses provided for a Library Committee consisting of the Campus Librarians, Assistant Librarians and one member of the teaching staff of each faculty of the Campus nominated by the Faculty Council (section 20. (2) (a) p.25). The Universities Act No. 16 of 1978 provided for the establishment of the Library Committee as an ad hoc Committee of the Senate, does not give its composition, but empowers the Senate "to specify their terms of reference; to consider their reports and to either approve such reports, whether with or without modification, or to reject such reports;"(section 46 (6)(vii) p. 27).

The 1972 Act also provided for an Academic Committee of a Faculty where "the person in charge of the library of the Faculty if any, or the person in charge of the Campus library" was a member. The Academic Committee had the authority to appoint a Library standing committee along with other standing committees. This provision was continued in the subsequent act Universities Act no. 16 of 1978 which is in force at present. Even under this act the faculty included the Librarian or his nominee as an ex-officio member but this provision was removed by the Universities (Amendment) Act, No, 7 of 1985.

The Inter University Committee of Librarians (IUCL) of the UGC which was established in 1989 provided a forum for the librarians to discuss matters of common interest, and provided a link to have direct access to the UGC. The committee is chaired by a member of the UGC. In 2003, the IUCL was reconstituted as the Standing Committee of Library and Information Sciences 
(SCOLIS) which attends to most matters relating to libraries. The SCOLIS have been able to develop an Inter-library loan code, Library standards, Performance indicators, Information policy for libraries and Recruitment and promotions scheme for librarians. On the request of SCOLIS, the Quality Assurance and Accreditation (QAA) Council and the UGC introduced external quality process for university libraries.

\section{Staff structure:}

The libraries had their staff structure based on functions: Reader Services, Acquisitions, Cataloguing, Periodicals, etc. and these sections were looked after by an Assistant Librarian. In addition there were branch libraries attached to faculties, and sometimes departmental libraries functioning under the relevant heads of departments. In 1959, University of Ceylon library had four professionally qualified librarians. In addition to the professional staff the libraries have three other categories of staff: Library Assistants who are attending to most of the routine operations, library attendants who are looking after the shelving of library materials, and labourers attending to cleaning work.

In 1992 the UGC established norms for university library staff. According to the norms the Professional Staff/Reader ratio was 1:400, and professional staff should comprise $15 \%$ of the total staff cadre. 40\% was reserved for paraprofessional staff, $25 \%$ for support staff, and $20 \%$ for labourers. However, most of the universities are unable to get the required cadre based on these norms for their libraries.

In 1982, a position of Assistant Registrar/ Library Services was created to provide an opportunity for the qualified senior library assistants to get promotions by reserving $25 \%$ of senior staff positions. 
It is regrettable, that the University Grants Commission has paid only a lip service to the promotions of library staff specially the senior library staff. Documentary evidence is not available of the date of the establishment of the recruitment and promotion scheme for the senior library staff which was in existence until May, 2010 but the scheme is reproduced in the "Schemes of Recruitment and Procedures for Appointment to the University Staff" compiled by Abeyratne and distributed by the UGC in 1985 . The only revision which came before 2010 was the circular 653 (14.11.1995) which made provision for the promotions and salary adjustments to the posts of Assistant Librarian, Senior Assistant Librarians grade I and II. It is also important to note here that the recruitment and promotion scheme of academic staff (lecturers) was revised several times during this period (Commission circulars 721, 723, 838, $869,897)$ and also of the administrative staff. A proposal for a revised scheme was proposed by SCOLIS for the first time in 1998, but the process took 12 long years to be accepted by the Commission and issue the circular in 2010 .

\section{Staff training:}

Since the establishment of the universities until the late 1960s the probationary Assistant Librarians were provided with study leave abroad which entitled them to a living allowance and allowance to cover tuition and examination fees for a period of one year to obtain the post-graduate qualifications.

As the libraries were expanding, and the University of Peradeniya realizing the need for professional training commenced a Post-graduate Diploma course in 1961 , but it had to be abandoned due to various problems. Bonny in his report states that this one-year post-graduate diploma in Librarianship should be open for non-graduates in the first five years considering the acute shortage of 
professionals in the country. Further he said that in-service training programmes should be conducted.

On the recommendation of the Committee on Higher Education appointed in 1972, the university teachers and Assistant Librarians were encouraged to undertake post-graduate work in the country itself. From around 1968 to 1974 until the Department of Library Science was established at the University of Kelaniya and Post Graduate Diploma in Library \& Information Science (LIS) commenced, there were no opportunities for Assistant Librarians to obtain post-graduate qualifications, in order to get the promotions. University of Kelaniya also started an Advanced Diploma in LIS which was equivalent to the three tiered professional course conducted by the Sri Lanka Library Association, and this course catered mainly for Library Assistants in the Universities and librarians in the government sector.

At the inaugural seminar on Library Management held on 02 May 1987 a postgraduate institute for the training of librarians was proposed.

"The objectives of the proposed Post-graduate Institute were:

(i) to promote advanced education and research in library and information sciences, and related fields.

(ii) to promote systematic study and research into the field of information science generally and into problems of management of information centres peculiar to Sri Lanka and the Asian region.

(iii) to liasise and co-operate with institutes having similar objectives and functions with a view to developing professional education in this field." (Kalpage, 1987) 
The institute was expected to conduct full time as well as part-time courses for postgraduate degrees and diplomas, provide in-service training programmes, promote research and publications for professional advancement, and also evaluate and accredit courses in library and information sciences. However, this proposal never saw the light of the day due to the high capital cost involved.

National Institute of Library and Information Science (NILIS) which was established as an Institute affiliated to the University of Colombo and as part of the World Bank funded General Education project (GEP II) in 1999 had as its objectives:

(i) To develop manpower resources equipped with appropriate professional knowledge, skills and competence capable of contributing effective in:

a. Planning, organization, management, operation and development of library services, systems, centres and programmes,

b. Teaching, and research in the field of LIS;

(ii) To promote professional advancement of those already in service in the LIS field by organizing and conducting continuing educational programmes for their training and re-training;

(iii) To conduct research and to disseminate the results to such research through publications, seminars, workshops and extension services;

(iv) To liaise with and establish cooperation and link programmes with other national and international institutes having similar objectives and allied interests. 
NILIS over the years have organized several certificate, diploma, and postgraduate programmes. The Faculty of Graduate Studies of the University of Colombo commenced a master in Library and Information Science programme in 1993 mainly to provide for a research degree in LIS which was a requirement for the confirmation and promotion of Assistant Librarians in the university system.

At present, the Faculty of Graduate Studies of the University of Colombo, Department of Library Science at the University of Kelaniya and NILIS conducts a Master's and doctoral degree programmes in addition to their other LIS programmes.

\section{Status of Automation of library operations:}

The process began consequent to the decisions taken at the seminar on Library Management held on 02 May 1987 followed by a proposal submitted to the UGC by the Librarian, University of Peradeniya on 'Computerization of University Libraries in Sri Lanka'. As a result, in 1989 a computer each was given to universities by the UGC. The libraries began computerizing their catalogues using ISIS an integrated software package developed and distributed free by UNESCO. At present some universities are using proprietary library management systems such as Alice for Windows, and Libsys for their library operations. A noteworthy step forward is the development of the integrated library management system ISURU based on free software Koha which has been implemented in the University of Ruhuna Library. Most libraries have now made their library catalogues available over the web.

The introduction of electronic resources in libraries was made in 2002 with a gift subscription of three full text databases from International Network for the Availability of Scientific Publications (INASP). From 2003 to 2007 funding and 
training came through Sida/SAREC Library Support project coordinated by the Library, University of Colombo. Now the universities are faced with a new challenge having a user community accustomed to using e-resources for their academic pursuits on one side and lack of finances for the development of infrastructure, equipment, subscription to e- resources, and trained man power on the other.

\section{Conclusion}

During the period which began in 1921 with the establishment of the library of the University College the university libraries have grown in number and the collections, staff have expanded. Along with this expansion, challenges faced by the librarians also have increased.

De Souza (1975) commenting on the responsibilities of libraries state, "The entire object of the library's professional exercises should be to make the reader self-reliant in his approach to the resources that await him. A university must ensure that a student has the time and right conditions to educate himself, and the university library is the best workshop or laboratory for selfinstruction that exists. At a time when demands on university libraries are greater than ever before, this responsibility is all the greater." (p.133)

She further states that librarians must use most elaborate techniques of instruction and guidance for the use of library resources, and re-orient the attitude of the library staff to find the right books. If best use of the library is to be achieved, lectures of introduction, handbooks and leaflets which are seldom read are not sufficient, but these activities to be extended and activated throughout the career of the undergraduate. 
Lack of senior professional staff that can provide leadership seems to be the main problem inhibiting the development of libraries. The University of Ruhuna appointed a librarian only in 2009 after 31 years of its establishment as a campus in 1978, and at present four universities are without librarians. Most universities do not have adequate buildings to house their collections and cater to the increasing number of students, lack of finances for equipment, furniture, books and periodicals, and electronic resources. For today's university librarian the march forward would be rough with several barriers to overcome in a challenging environment.

\section{References}

Bonny, Harold V 1961, Library services for Ceylon. Ministry of Cultural Affairs, Colombo

Commission on University of Ceylon. Report (Sessional papers XXIII 1959)

De Silva, KM \& Peiris, GH (ed.) 1995 The university system of Sri Lanka: vision and reality, International Centre for Ethnic Studies, Kandy.

De Silva, WRG 1985, Libraries and Librarianship in Sri Lanka, with special reference to University Libraries 1942-1983, MLib thesis, Monash university

De Souza, Violet 1975, 'University education and libraries in Sri Lanka' in Ishvari Corea (ed), Libraries and people, Colombo Public Library, Colombo

Goonethileke, HAI 1975, 'A university, its library, and the undergraduate', in Ishvari Corea (ed), Libraries and people, Colombo Public Library, Colombo

Inter University Committee of Librarians 1997, Institute of Library and Information Science: project proposal prepared for the University Grant Commission

Jennings, Sir William Ivor, The Road to Peradeniya: an autobiography edited by HAI Goonetileke Colombo, Lake House Investments, 2005

Kalpage, Stanley 1988 Higher Education: themes and thoughts, UGC, Colombo 
Senadeera, NTSA 1987 Computerization of University libraries in Sri Lanka: report prepared for consideration by the Inter University Committee of Librarians, UGC

Senadeera, NTSA, 'The first librarian of the University of Ceylon' in University of Ceylon/University of Peradeniya Golden Jubilee Souvenir 1942-1992

Sri Lanka 1966, Higher Education Act No. 20, Government Publications Bureau, Colombo

Sri Lanka 1978, Universities Act No. 16, Government Publications Bureau, Colombo

Sri Lanka 1985, Universities (Amendment) Act No. 7, Government Publications Bureau, Colombo

Sri Lanka 1972, University of Ceylon Act No. 1, Government Publications Bureau, Colombo

Universities Commission 1963, Report of the University Commission 1962, Government Publications Bureau, Colombo

University Grants Commission 1992, UGC/AC/2/20(III) of 08 October 1992 "Norms for Library Staff of the Universities", UGC, Colombo

University of Ceylon. Calendar for the session 1954-55. Ceylon University Press University of Kelaniya. Sri Lanka News Letter vol. 3 August 2007 